\title{
Measurement of Continuous Cooling Transformation Curve and High Temperature Mechanical Properties for 12Mn Steel
}

\author{
SHENGTAO QIU, JUN WEI
}

(National Engineering Research Center of Continuous Casting Technology, Central Iron and Steel Research Institute, Beijing 100081, China)

Abstract: The dilatometer curves of continuous cooling transformation of $12 \mathrm{Mn}$ steel were measured with Formastor-F II thermal mechanical simulator. The steel's undercooled austenite phase continuous cooling transformation curves ( CCT curves) were established by means of the dilatometer method and the metallographic-hardness measurement method. The effect of cooling rate on microstructure and hardness of the steel was studied. CCT curve of test steel was simulated by JMatPro. The results show that the $\mathrm{Ac}_{1}$ and $\mathrm{Ac}_{3}$ of the experimental steel are $692^{\circ} \mathrm{C}$ and $855^{\circ} \mathrm{C}$; the microstructure obtained is made of ferrite, pearlite and bainite. The ferrite transformation and pearlite transformation occur at a slower cooling rate, in which the ferrite is dominant. When the cooling rate is greater than $4.25{ }^{\circ} \mathrm{C} / \mathrm{s}$ bainite transformation happens. As the cooling rate increases, microstructure or grains become finer. The hardness of the tested steel with increasing cooling rate shows a trend of first fast increase and soon decrease. The simulation results are consistent with the measured CCT law. The high temperature mechanical properties of $12 \mathrm{mn}$ steel round billet were tested by gleeble-1500d thermal / mechanical simulator. The tensile strength, reduction of area and stress-strain curves of the billet were obtained in the range of $600-1300{ }^{\circ} \mathrm{C}$.

Keywords: $12 \mathrm{Mn}$ steel; round billet; thermal mechanical simulation; CCT curve; diatometer method; JmatPro; tensile strength; the reduction of area; stress-strain curve; Thermal-cal software

The continuous cooling transformation curve of undercooled austenite is also called CCT curve. It

can be used as the basis for the analysis of austenite transformation and microstructure and properties of transformation products in continuous cooling process, and also as an important reference for the formulation of heat treatment process of steel ${ }^{[1]}$. High temperature mechanical properties are the characteristics of steel in the process of casting, which is an important basis for judging the crack 
generation.

When $12 \mathrm{Mn}$ steel is used in the production of oil pipelines, the welding and mechanical properties of the materials are strictly required, and the excellent comprehensive properties are also needed. In addition, because $12 \mathrm{Mn}$ belongs to peritectic steel, during the casting process, the round billet is prone to crack defects, which ultimately affect the final performance. Whether round billet appears crack is closely related to the cooling speed. In addition, the high temperature mechanical properties of the steel itself are also the internal factors influencing the round billet cracks. However, there is no CCT curve and high temperature mechanical property data of $12 \mathrm{mn}$ steel, so it is necessary to assess the CCT curve and high temperature mechanical property of this steel.

In this paper, the transformation characteristics of undercooled austenite at different cooling rates of the steel are measured by means of thermal expansion and hardness metallography, and the CCT curve of the $12 \mathrm{Mn}$ steel is drawn. The CCT curve is simulated by JMatPro. The mechanical properties of $12 \mathrm{Mn}$ at high temperature were measured by Gleeble $1500 \mathrm{D}$, and the cause of the third brittle zone was verified by thermal-cal.

\section{Experimental procedure}

The materials used in this work which were low carbon steels for pipeline application, were firstly taken from round billet ( shown in Figure 2) and its production process is illustrated in Figure 1 , and subsequently the round billet was hot forged to the rods of $25 \mathrm{~mm}$ in diameter. Specimens used in the undeformed conditions (10-mm long cylindrical tubes with a diameter of $3 \mathrm{~mm}$ ) were cut from the forged rods. Chemical compositions of $12 \mathrm{Mn}$ steel are listed in Table 1. 


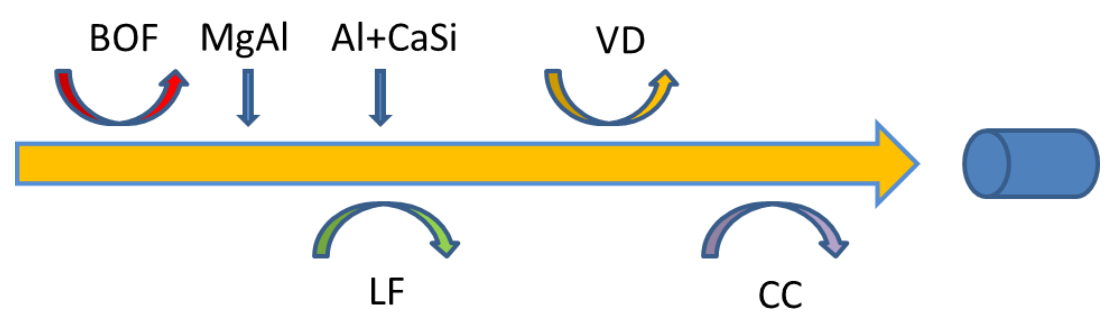

Fig. 1-Flow chart of production process of $12 \mathrm{Mn}$ steel round billet

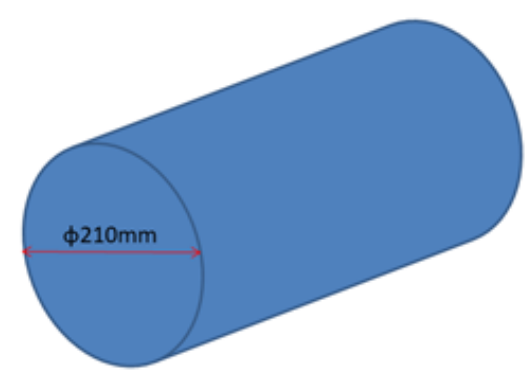

Fig. 2-Sample from 12Mn round billet

Table 1 Chemical composition of steel sample \%

\begin{tabular}{cccccccc}
\hline Element & $\mathrm{C}$ & $\mathrm{Si}$ & $\mathrm{Mn}$ & $\mathrm{P}$ & $\mathrm{S}$ & Alt & T.O \\
\hline $12 \mathrm{Mn}$ & 0.1 & 0.28 & 1.24 & 0.013 & 0.002 & 0.03 & 0.0025 \\
\hline
\end{tabular}

The size of thermal expansion sample and equipment of thermal expansion instrument used in this experiment is illustrated in Figure 3. 


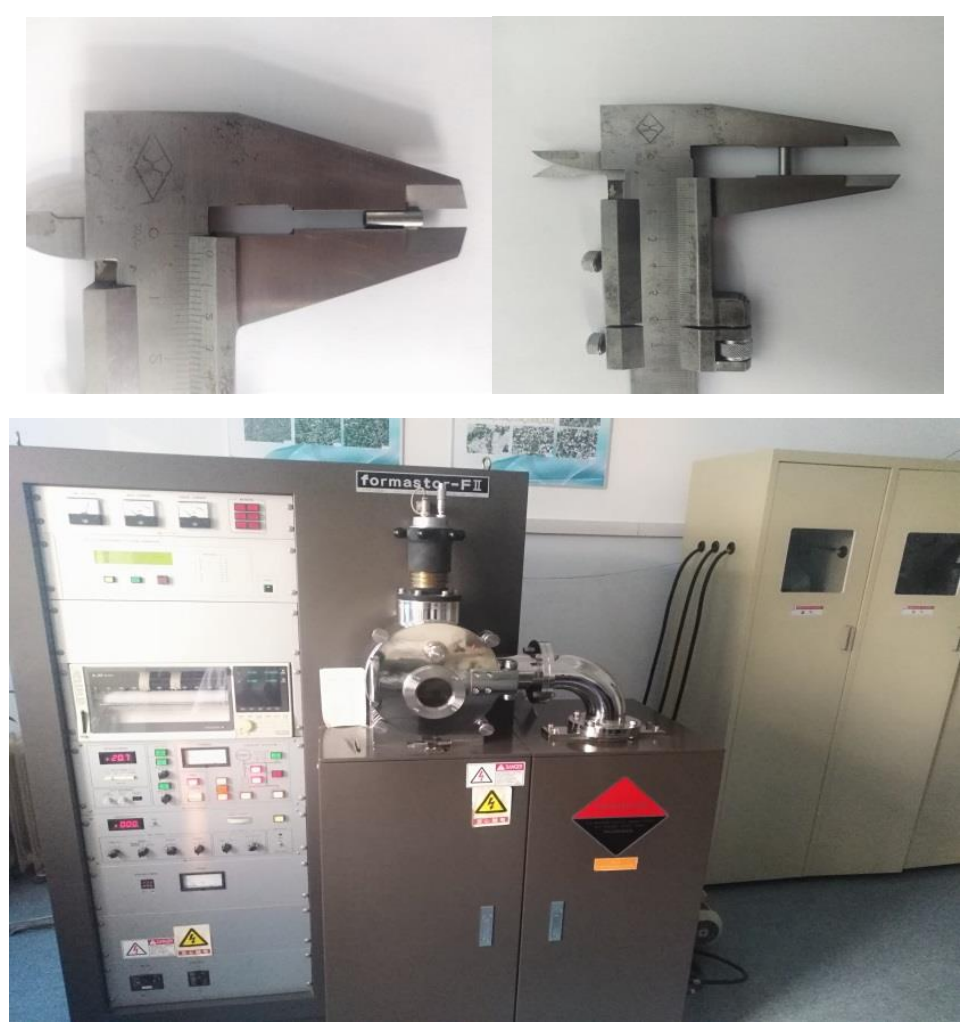

Fig. 3-Thermal expansion apparatus and sample size

The static thermal simulation test scheme: the static (without hot deformation) CCT diagrams were conducted on a Formastor-F IIthermal mechanical simulator dilatometer(Figure 3), and the corresponding specimens were firstly austenitised for approximately $5 \mathrm{~min}$ at $950{ }^{\circ} \mathrm{C}$ (Figure 1), and then cooled at the linear cooling rates of $0.028,0.056,014,0.28,0.85,1.7,4.25,8.5,17$ and $42.5^{\circ} \mathrm{C} / \mathrm{s}$, respectively. Then $3 \%$ nitric acid solution was used to corrode the sample, which was observed and analyzed under metallographic microscope. The transformation point is obtained by the expansion curve and the tangent method. Finally, the Vickers hardness is determined.

The process route (Figure 4) is as follows: 


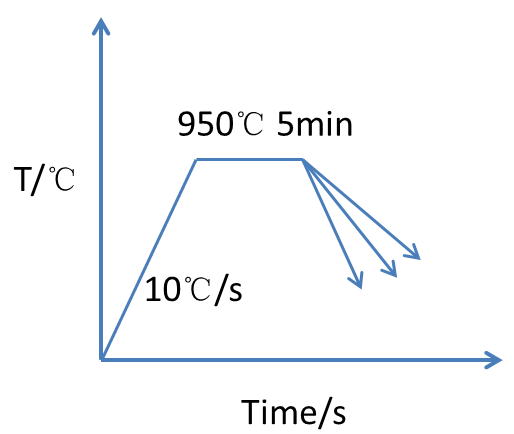

Fig. 4 Thermal simulating process of $12 \mathrm{Mn}$ steel

\section{Results and discussion}

\subsection{Determination of critical point}

According to $\mathrm{Yb} / \mathrm{T}$ 5128-93, when the static critical point of steel is measured by expansion method, its heating and cooling rate should be less than $200{ }^{\circ} \mathrm{C} / \mathrm{h}$. There are two methods to be determined the critical point from the expansion curve: vertex method and tangent method. The vertex method takes the vertex with the most obvious inflection on the expansion curve as the critical point.

The advantage of this method is that the inflection point is obvious and easy to determine, but the critical point determined by this method is not the real critical point, and its determined transition start temperature will be higher than the real one, and the transition end temperature will be lower than the real one. The critical point determined by this method will not have obvious influence on the actual heat treatment process, but will have a certain influence on the position of CCT curve. Therefore, tangent method is generally applied in CCT curve measurement. Tangent method takes the separation point between the straight line of the expansion curve and the curve part as the critical point. The advantage of this method is that it is close to the real transition start and end temperature.

Figure 5 displays the CCT curve of $12 \mathrm{Mn}$ steel sample. The critical points of transformation of 12Mn steel after hot deformation are: $\operatorname{Ar} 1=615^{\circ} \mathrm{C}, \operatorname{Ar} 3=762{ }^{\circ} \mathrm{C}, \operatorname{Ac} 1=692{ }^{\circ} \mathrm{C}, \operatorname{Ac} 3=855^{\circ} \mathrm{C}$.

The dilatation curves obtained while cooling from three different peak temperatures are shown in 
Figure 5. The $\gamma$ and $\alpha$ phases individually experience linear contraction with a fall in temperature. At the temperature where $\gamma$ starts transforming to $\alpha$, the specimen undergoes an increase in radial dilatation until complete transformation to the $\alpha$ phase is achieved. The points at which the tangents deviate from the $\mathrm{g}$ and a lines are the transformation start (Ts) and finish (Tf) temperatures, respectively, and are shown in Figure 5. While Ts corresponds to 5\%, Tf corresponds to 95\% of the transformed fraction. The transformation temperatures are obtained from the dilatation data of various thermal treatments. Thermal treatments are presented in Table IV.
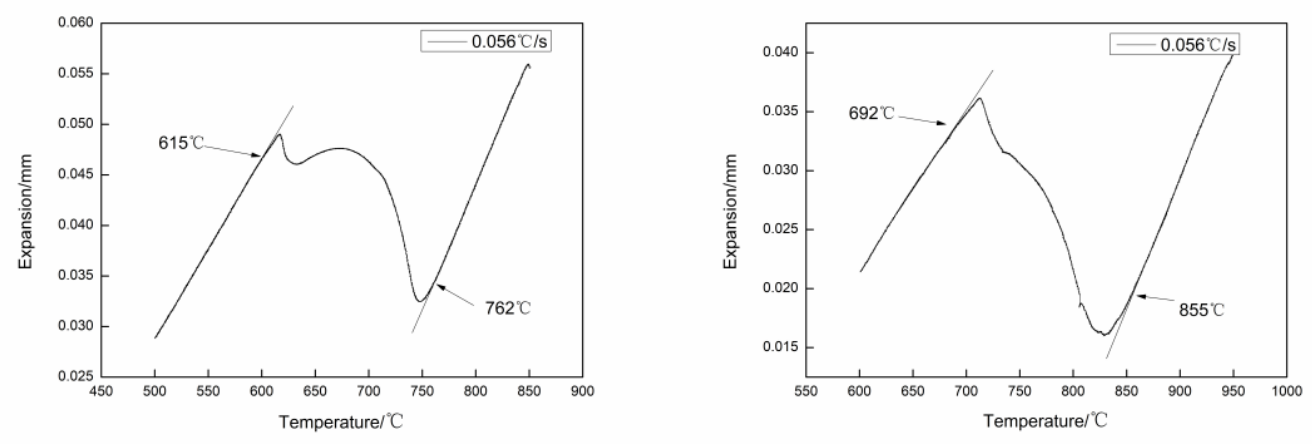

Fig. 5 -Dilametric curve: (a) heating, (b) cooling

\section{2 Drawing of CCT curve}

Figure 6 demonstrates the thermal expansion curves of the test steel at different cooling rates and the continuous cooling transformation temperature of undercooled austenite determined by the tangent method and metallographic hardness method. Table 3.7 exhibits the transformation point of undercooled austenite and the corresponding transformation structure. The phase transformation temperature and phase transformation structure of undercooled austenite at different cooling rates are determined based on the above metallographic structure and the tangent edge points on the cooling expansion curve. The CCT curves obtained according to Table 2 are shown in Figure 6 . The number next to the cooling curve is the cooling rate, and the number below the cooling curve is the hardness of phase transformation structure (HV) at this cooling rate.| 

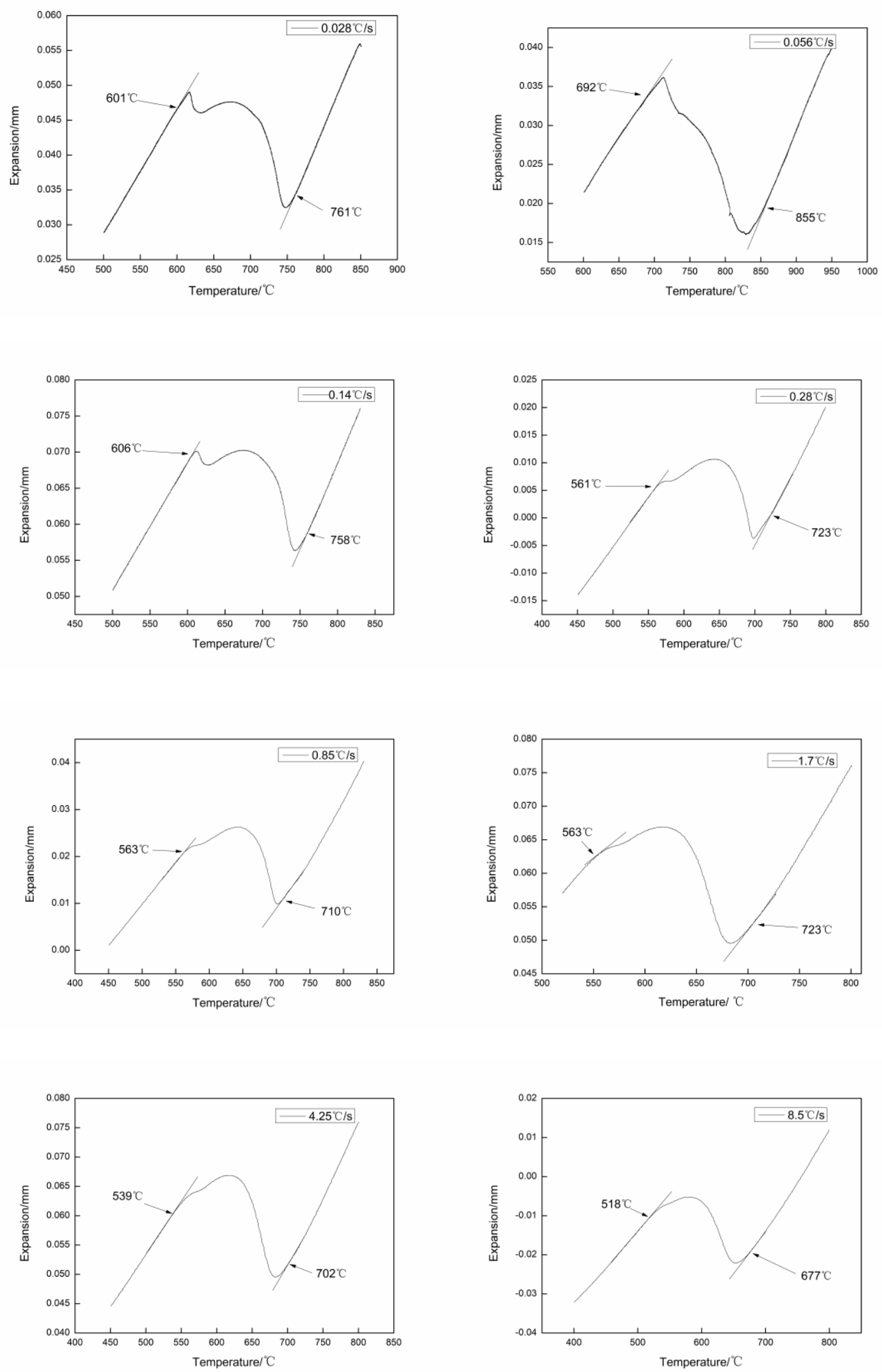

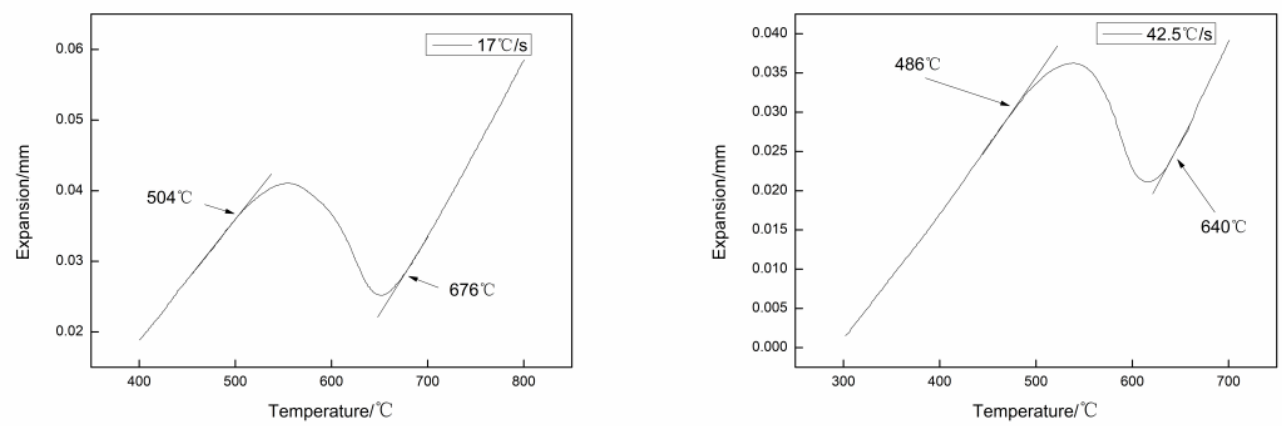

Fig. 6-Transformation point of undercooled austenite of test $12 \mathrm{Mn}$ steel under different cooling rates 
Table 2 Phase transition under different cooling rates

\begin{tabular}{cccccc}
\hline $\begin{array}{c}\text { The cooling rate } \\
/{ }^{\circ} \mathrm{C} . \mathrm{S}^{-1}\end{array}$ & $\begin{array}{c}\mathrm{A}-\mathrm{Fs} \\
/{ }^{\circ} \mathrm{C}\end{array}$ & $\begin{array}{c}\mathrm{A}-\mathrm{Ff} \\
/{ }^{\circ} \mathrm{C}\end{array}$ & $\begin{array}{c}\mathrm{A}-\mathrm{Bs} \\
/{ }^{\circ} \mathrm{C}\end{array}$ & $\begin{array}{c}\mathrm{A}-\mathrm{Bf} \\
/{ }^{\circ} \mathrm{C}\end{array}$ & Microstructure \\
\hline 0.028 & 761 & 601 & & & $\mathrm{~F}+\mathrm{P}$ \\
0.056 & 762 & 615 & & & $\mathrm{~F}+\mathrm{P}$ \\
0.14 & 758 & 606 & & & $\mathrm{~F}+\mathrm{P}$ \\
0.28 & 723 & 561 & & & $\mathrm{~F}+\mathrm{P}$ \\
0.85 & 710 & 563 & & & $\mathrm{~F}+\mathrm{P}$ \\
1.7 & 723 & 563 & & & $\mathrm{~F}+\mathrm{P}$ \\
4.25 & 702 & & 539 & 539 & $\mathrm{~F}+\mathrm{P}$ \\
8.5 & 677 & & 617 & 518 & $\mathrm{~F}+\mathrm{P}+\mathrm{B}$ \\
17 & 676 & & 609 & 504 & $\mathrm{~F}+\mathrm{P}+\mathrm{B}$ \\
42.5 & 640 & & 577 & 486 & $\mathrm{~F}+\mathrm{P}+\mathrm{B}$ \\
\hline
\end{tabular}

\section{3 Microstructure and Vickers hardness}

Although the expansion method and tangent method can determine the transformation point, when the transformation amount is small, the transformation point on the curve is not obvious enough, and the measurement accuracy is not enough. As an effective means, the metallographic method can improve the measurement accuracy. The hardness method is an important method to determine the transformation products when the transformation products in the micrograph are sometimes difficult to $\operatorname{distinguish}^{[2]}$.

Figure 7 displays the microstructure photos under different cooling rates, and Figure 8 shows the corresponding Vickers hardness values under different cooling rates. 

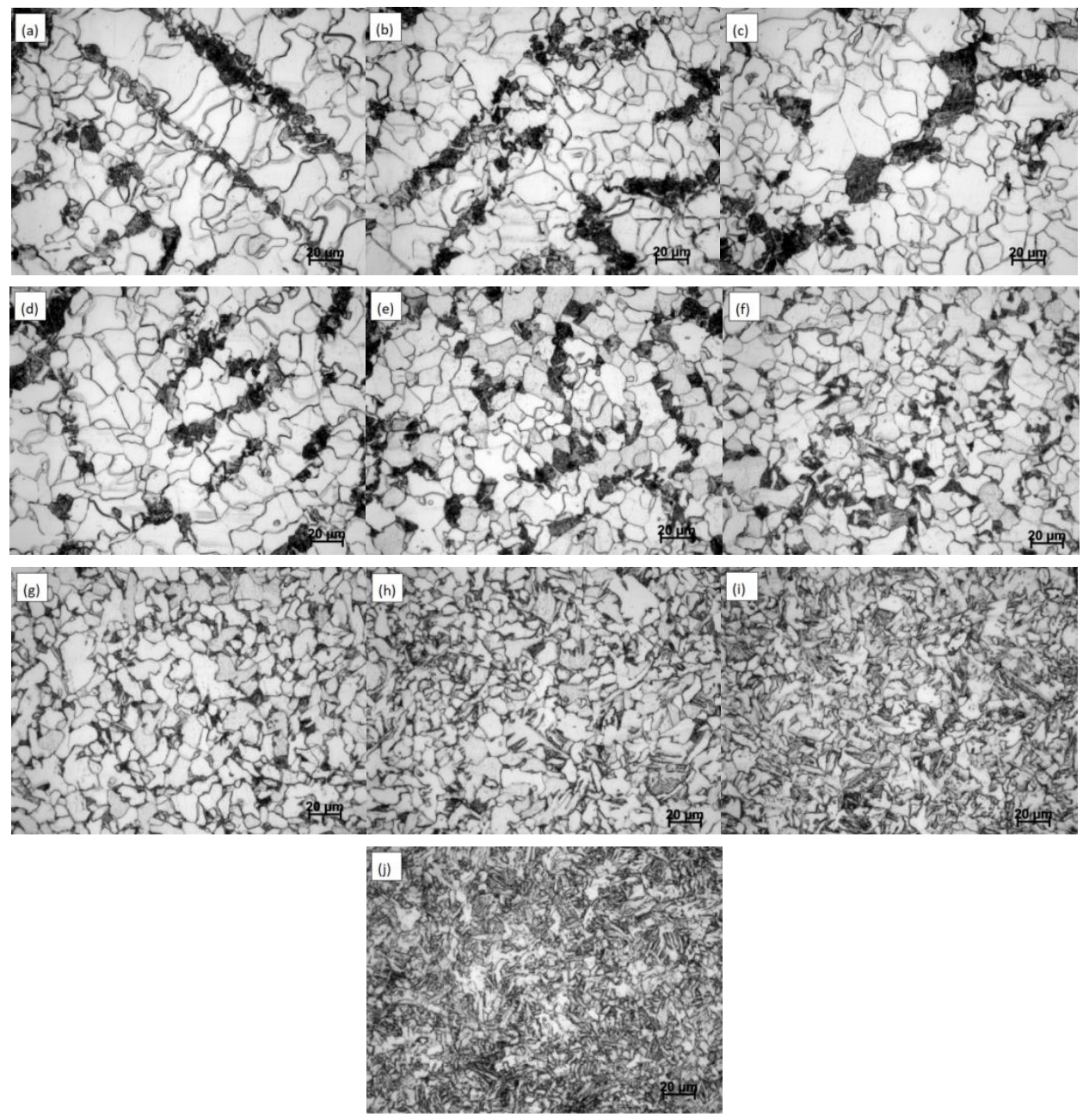

Fig. 7-Microstructure of $12 \mathrm{Mn}$ steel after continuous cooling transformation at different cooling rates (a) $0.028^{\circ} \mathrm{C} / \mathrm{s}$; (b) $0.056^{\circ} \mathrm{C} / \mathrm{s}$; (c) $0.14^{\circ} \mathrm{C} / \mathrm{s}$; (d) $0.28^{\circ} \mathrm{C} / \mathrm{s}$; (e) $0.85^{\circ} \mathrm{C} / \mathrm{s}$; (f) $1.77^{\circ} \mathrm{C} / \mathrm{s}$; (g) $4.25^{\circ} \mathrm{C}$

$$
/ \mathrm{s} ;(\mathrm{h}) 8.5^{\circ} \mathrm{C} / \mathrm{s} ;\left(\text { i) } 17^{\circ} \mathrm{C} / \mathrm{s} ;\left(\text { j) } 42.5^{\circ} \mathrm{C} / \mathrm{s}\right. \text {; }\right.
$$

Based on the different cooling rate, the transformation structure of undercooled austenite can be divided into ferrite + pearlite and bainite. In $0.028-4.25{ }^{\circ} \mathrm{C} / \mathrm{s}$, the transformation structure of undercooled austenite is white ferrite + black pearlite. Under this cooling rate, with the rising of the cooling rate, the pearlite area is smaller and more dispersed. In $0.028{ }^{\circ} \mathrm{C} / \mathrm{s}$ and $0.056{ }^{\circ} \mathrm{C} / \mathrm{s}$, the structure banded. This is the dendrite segregation caused by alloying elements with small diffusion coefficient under non-equilibrium conditions, which will be extended to band structure in the subsequent continuous casting process ${ }^{[3]}$. 
In the relatively low cooling rate range of $12 \mathrm{mn}$ steel, the first eutectoid ferrite nucleates at the austenite grain boundary. Due to the diffusion of alloy elements, the coherent relationship between austenite and ferrite interface is destroyed, resulting in the gradual growth of low carbon ferrite. It is generally believed that the growth process of equiaxed ferrite is process that ferrite grain boundary moves. The pearlite transformation of austenite will occur through the diffusion of $\mathrm{C}$ and other alloy elements when the above-mentioned eutectoid ferrite precipitates and grows up until $\mathrm{C}$ enrichment and the austenite of alloying elements reach the eutectoid composition stage.

Under faster cooling rate $\left(8.5-42.5^{\circ} \mathrm{C} / \mathrm{s}\right)$, the transformation of undercooled austenite results in granular bainite. The pre eutectoid ferrite and pearlite are precipitated first. Characteristics of granular bainite: the distribution of matrix ferrite is an island structure, and the island structure is a long strip or granular with discontinuous parallel arrangement, in which the long island ferrite matrix is parallel needle like ferrite. The main structure of $12 \mathrm{Mn}$ is discontinuous strip. The process of elongated granular bainite is: during the growth of ferrite, the austenite between ferrite and ferrite front is rich in carbon, and the driving force of transformation decreases. When the carbon content in austenite reaches a certain degree, transformation stops ${ }^{[4-5]}$. In addition, the carbon concentration does not wash out the carbide, and the carbon rich austenite island structure forms bainite during the cooling process. 


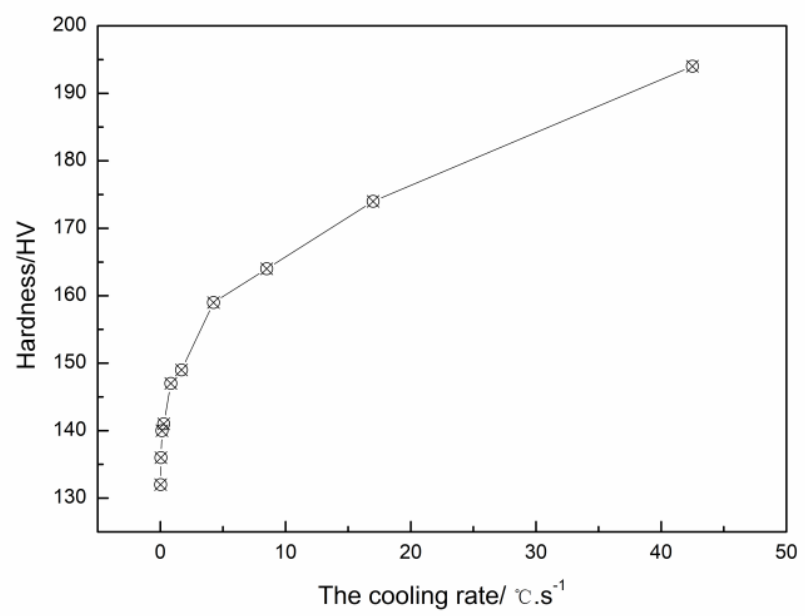

Fig. 8-Hardness of $12 \mathrm{Mn}$ steel at different cooling rates

As seen from Figure 8, the hardness of $12 \mathrm{mn}$ steel increases from $132 \mathrm{hv}$ to $192 \mathrm{hv}$ in the process of cold speed rising from $0.028^{\circ} \mathrm{C} / \mathrm{s}$ to $42.5^{\circ} \mathrm{C} / \mathrm{s}$. This reason is that with the increase of cooling rate, the grain refinement reduces the nucleation and diffusion ability of carbonitride, and the second phase is more dispersed; at the same time, the driving force increases, the dislocation density increases, and the hardness also increases. Therefore, with the rising of the cooling rate, the transformation mechanism gradually changes from diffusion to edge cutting, the diffusion ability of the second phase forming elements of microanalyses elements decreases, and the dislocation density grows. All these factors together make the hardness of $12 \mathrm{Mn}$ steel go up ${ }^{[6]}$.

\section{3 Drawing of CCT curve}

In terms of the expansion curve measured during the undercooled austenite cooling process, the transformation points at different cooling rates can be basically determined by the tangent method, microstructure and hardness analysis. Sign these points on the semi logarithmic coordinate of T-t and link the transformation points with a smooth curve to get the CCT curve of Figure $9^{[7]}$. Furthermore, mark the hardness of $\mathrm{Ac}_{1}$ and $\mathrm{Ac}_{3}$ at different cooling rates. 


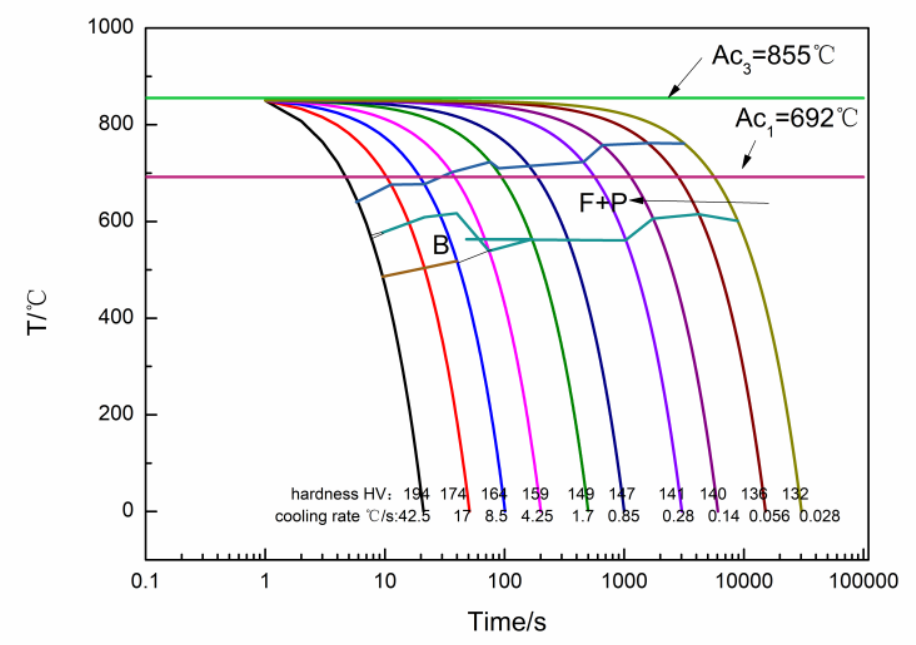

Fig. 9-Continuous cooling transformation curve of $12 \mathrm{Mn}$ steel(CCT diagram)

\section{JMatPro软件模拟CCT}

JMatPro is a software for calculating the phase diagram and material properties of iron and steel materials, which can be used by any researchers without too deep theoretical knowledge.

\section{CCT}

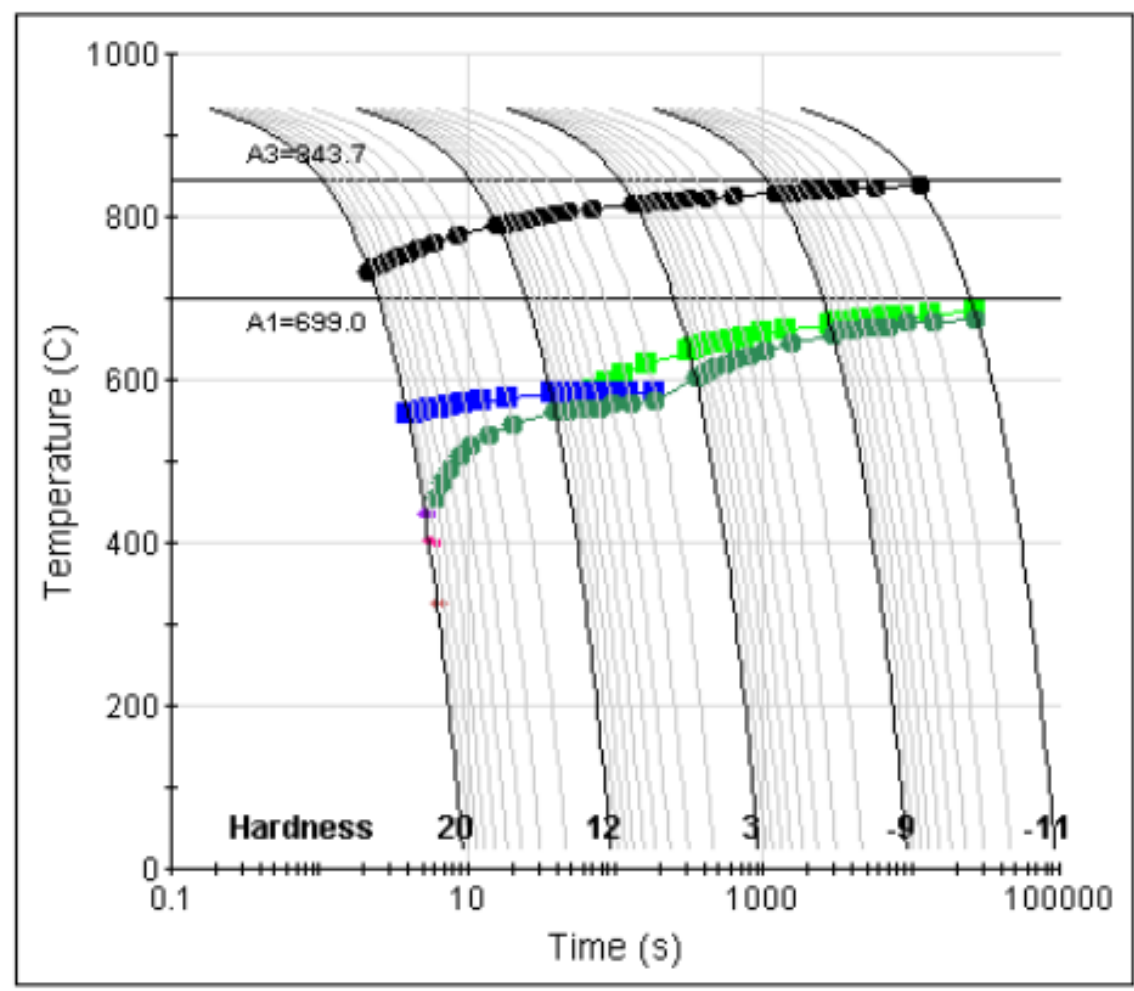

Ferrite(1\%)

Pearlite(1\%)

Bainite(1\%)

- Austenite(1\%)

* Martensite start

Martensite $50 \%$

Martensite $90 \%$

Austenitisation temperature (C) : 950.0

Grain size : 9.0 ASTM

Fig. 10-CCT curve of test steel simulated by JMatPro 
Figure 10 exhibits the CCT curve simulated by JMatPro for test $12 \mathrm{Mn}$ steel. Comparing CCT simulated by JMatPro and CCT simulated, it can be found that the simulated AC3 is $843.7^{\circ} \mathrm{C}$, and the tested AC3 is $855^{\circ} \mathrm{C}$. This may be because the simulated initial grain size is 9 , and the measured grain size is less than 9, namely, the original structure is coarse and the phase interface is less, so the transformation is also slow, and the final AC3 is larger. Therefore, the next step is to adopt the steel sample with grain size of grade 9 for CCT comparison. Moreover, due to the equipment factor, the curve of cooling rate in a large range of $12 \mathrm{Mn}$ steel cannot be measured, while JMatPro simulation is not limited by the cooling rate. So JMatPro can simulate the martensite, but the experiment can't get the martensite. However, the general rule is basically the same. This shows that the measured CCT curve data are available.

\section{高温力学性能}

Because the crack is not only related to the cooling rate, but also to the characteristics of the steel itself, it is necessary to study the high temperature mechanical properties of $12 \mathrm{Mn}$ steel.

The test sample is taken from the continuous casting round billet and sample size is demonstrated in Figure 11. The schematic diagram of temperature control is shown in Figure 12. High temperature mechanical property test at Gleeble 1500D.The sample is protected by argon, and shrinkage is adopted represents plasticity of steel in the cross section and tensile strength represents strength of steel.

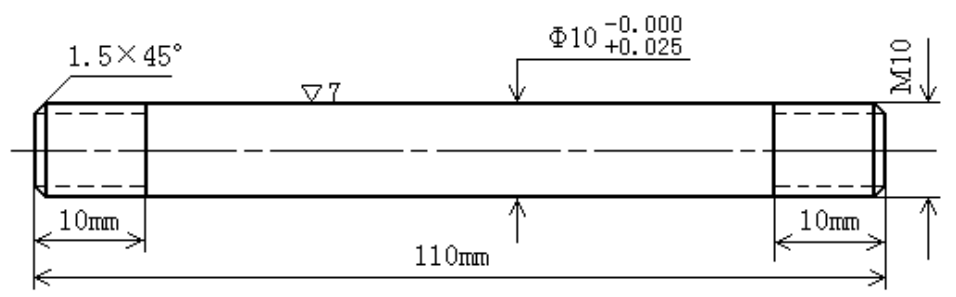

Fig. 11-Schematic diagram of the specimen 


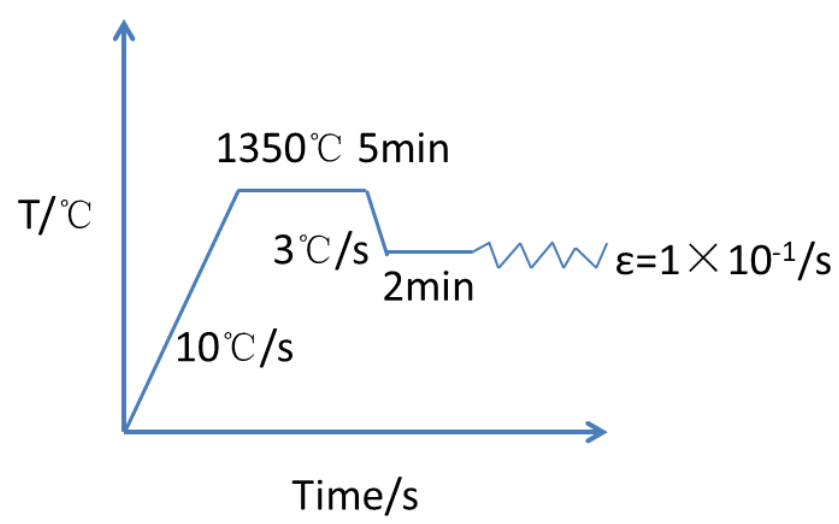

Fig. 12-Schematic diagram of tensile test

\section{3结果与讨论}

3. 1 Determination of tensile strength

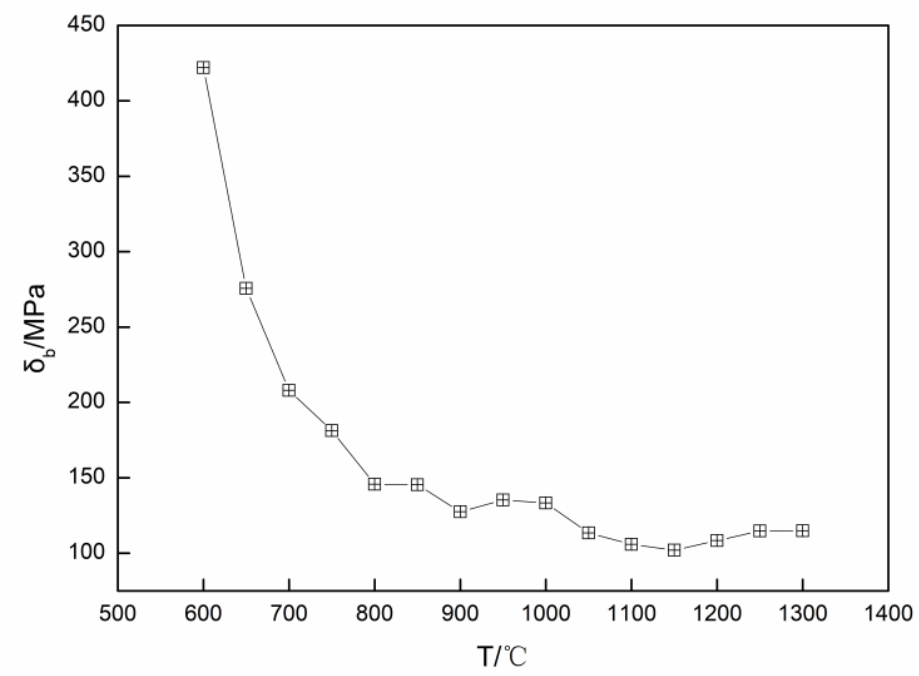

Fig. 13-Relationship of tensile strength with temperature for $12 \mathrm{Mn}$ round billet

It can be seen from Figure 13 that the tensile strength of the sample decreases sharply with the increase of temperature in the room at $600-800{ }^{\circ} \mathrm{C}$, and slowly with the increase of temperature at 800-1300 ${ }^{\circ} \mathrm{C}$. By fitting the data, the relationship between tensile strength and temperature is obtained by $\operatorname{Eq}(1)$ 


$$
\delta_{\mathrm{b}}=115.366+24355.136328 \exp (-0.01116 T)
$$

Compared with the same composition of ship plate steel ${ }^{[8]}$. the tensile strength of ship plate steel at $6500^{\circ} \mathrm{C}$ is $170 \mathrm{Mpa}$ and $12 \mathrm{mn}$ is $275 \mathrm{mpa}$. This shows that $12 \mathrm{mn}$ has strong resistance to external stress. When the temperature increases, the bonding force between atoms will decrease and dislocations will slip. The higher the temperature is, the easier the atom will transition, and then form a hole, which will result in a larger defect, namely a decrease in the macroscopic properties of the material. In addition, the increase of temperature will reduce the hindrance of the second and three-phase dislocation, and the reduction of pinning will reduce the tensile strength [9].

while the content of $\mathrm{Mn}$ and $\mathrm{Si}$ in $12 \mathrm{mn}$ is higher than that of ship plate steel, so the tensile strength will be high at the same temperature. The next step is to verify the effect of different alloy content on high temperature tensile strength.

\section{2Determination of reduction of area}

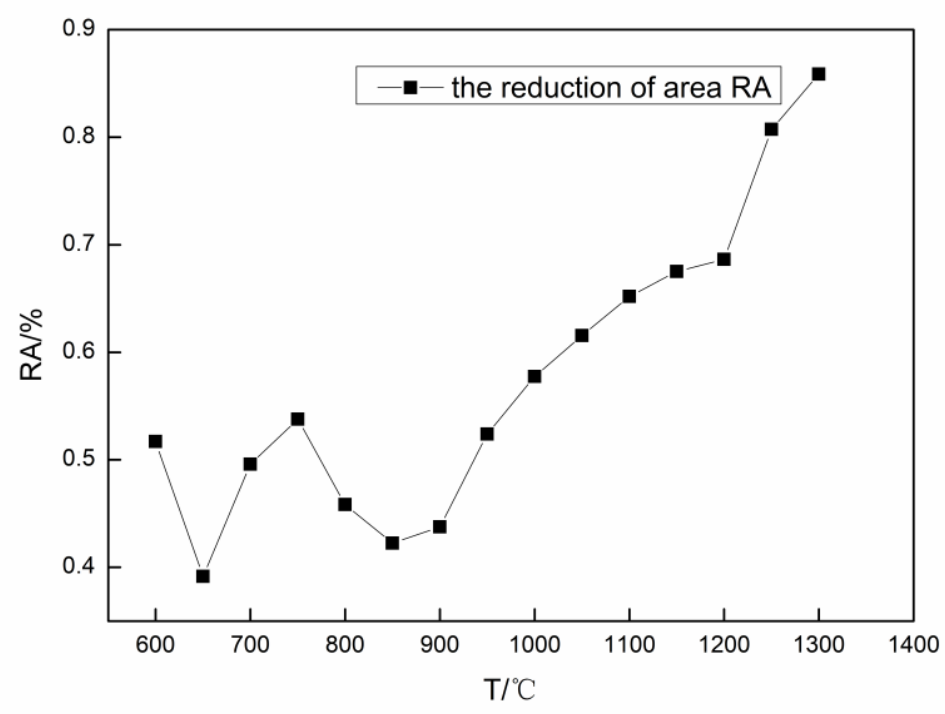

Fig. 14-Relationship of hot ductility of $12 \mathrm{Mn}$ round billet with temperature

The reduction of area RA is important for the plasticity of continuous casting slab, which reflects 
the strength of plastic deformation ability in the normal production process of continuous casting slab. The larger the numerical value is, the lower the possibility of surface crack will be. As shown in Figure 14 , there are three brittle zones between $600-1000{ }^{\circ} \mathrm{C}$, and the reduction of area decreases to a low value at $900{ }^{\circ} \mathrm{C}$, in which RA value is only $40 \%$. The third brittle zone is an important factor for the surface crack of slab, which is caused by the following two aspects ${ }^{[10-12]}$ :embrittlement in the process of $\gamma-\alpha$ transformation and $\gamma$ - grain boundary embrittlement. During the transformation from austenite to ferrite, the film like primary ferrite appears on the austenite grain boundary, and its strength value is just only 1 / 4 of that of austenite. The uneven deformation caused by the concentration of grain boundary eventually leads to the grain boundary embrittlement. The second phase particles at the austenite grain boundary slip under the external force, forming holes, so that the grain boundary becomes more brittle, and cracks will occur; in $1000-1300{ }^{\circ} \mathrm{C}$, the reduction of area $\psi$ is more than $60 \%$, which is the best plastic zone of $12 \mathrm{mn}$ steel continuous casting slab.

According to Suzuki Yangfu's research on the condensed semi melted steel ${ }^{[13]}$, when the reduction of area is less than $60 \%$, the plasticity will become very poor, and the surface cracks are easy to appear on the continuous casting slab. When the reduction of area is more than $60 \%$, the cracks will not appear on the surface of the slab.

The precipitation diagram of all phases of $12 \mathrm{mn}$ steel from $2000{ }^{\circ} \mathrm{C}$ to $500{ }^{\circ} \mathrm{C}$ is calculated by thermal-cal software, as shown in Figure 15. It can be seen from Figure 14 that the second phase between $600-1000{ }^{\circ} \mathrm{C}$ is AlN. Therefore, it can be proved that AlN particle is the second phase particle which leads to grain boundary embrittlement in austenite. 


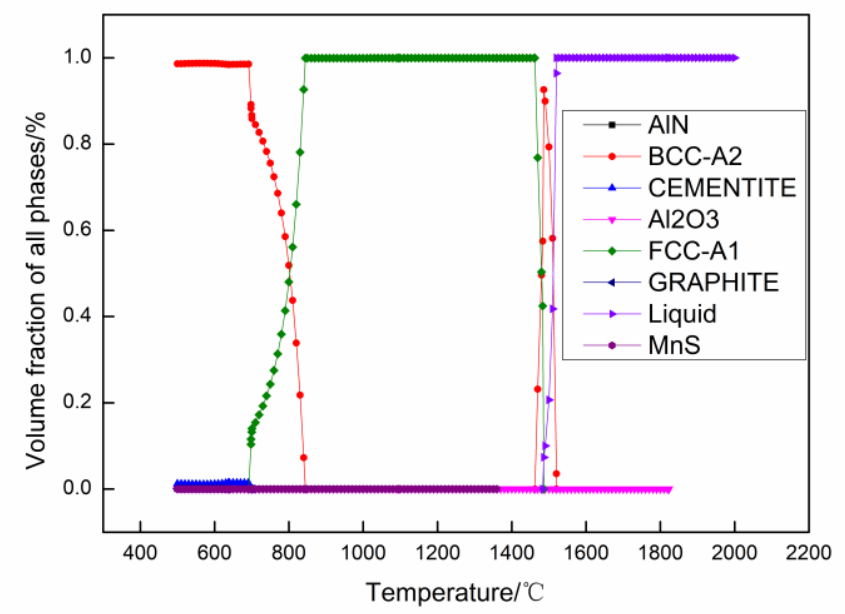

Fig. 15-Relation between temperature and equilibrium phases in steel $12 \mathrm{Mn}$

\section{3Measurement of stress-strain curve}

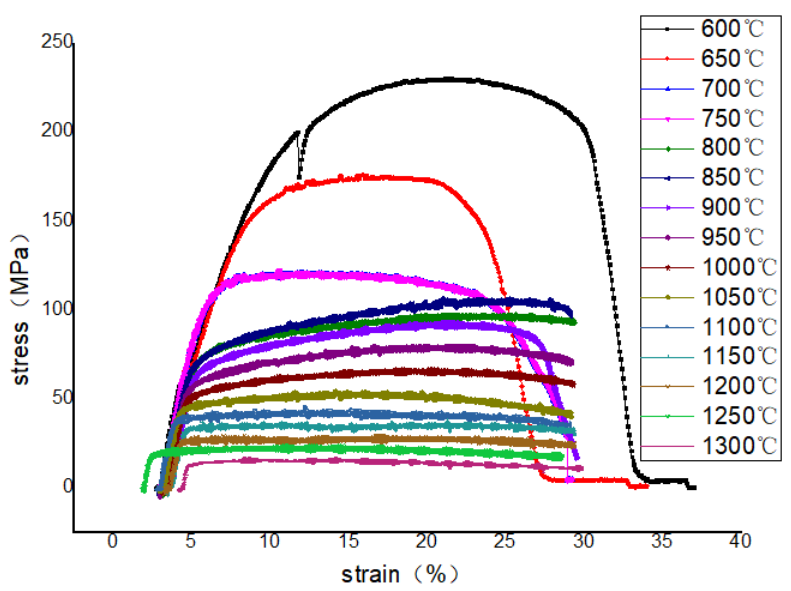

Fig. 16-Stress-strain curves of $12 \mathrm{Mn}$ round billet at different temperature

It can be seen from Figure 16 that at the beginning of deformation, the stress increases rapidly with the increase of strain, and the specimen is in the range of elastic deformation. When the increase of stress exceeds the yield strength, the specimen will produce plastic deformation, and the interface will be uniformly reduced, but the stress will keep increasing trend which decrease gradually. When the strain increases to a certain value, the stress decreases, and the stress and strain concentrate to a certain area, and plastic deformation occurs, namely "necking". It is worth noting that the curve of $600{ }^{\circ} \mathrm{C}$ has 
the feature of downward serration. This demonstrates that there is local instability in the deformation process, and the deformation in the tensile process is mainly slip or twin deformation. ${ }^{[14-15]}$. When the local area cannot bear the load, fracture occurs. The deformation resistance decreases with the decrease of temperature, because the temperature increases the activity of lattice atoms.

When the deformation temperature is high, it will exceed the elastic deformation and then plastic deformation will occur. In the plastic deformation stage, the dislocation density increases, the work hardening becomes stronger, the stress increases and the distortion energy increases, which is caused by the main driving force of dynamic recrystallization ${ }^{[16]}$. Dynamic recrystallization cross slipping and climbing make dislocations disappear gradually, which reduce the distortion energy, cause softening to counteract part of work hardening, and make the stress slowly reduce to the horizontal part ${ }^{[17]}$. At high temperature, the driving force of dislocation slip increases and dynamic recrystallization is easy to occur. Therefore, the stress of the specimen will decrease slowly with the increase of strain. This shows that the dynamic softening is the dominant factor when the deformation temperature is high. The higher the temperature is, the better the plasticity, the stronger the dynamic softening and the faster the softening rate. In fact, the peak stress will decline with the increase of deformation temperature ${ }^{[18]}$.

\section{Conclusions}

In order to analyze the causes of cracks, the CCT curves and high temperature mechanical properties of $12 \mathrm{Mn}$ steel were investigated, and the final conclusion of this work is as follows:

1) The critical temperature of $12 \mathrm{mn}$ steel is $\mathrm{Ac} 1=692^{\circ} \mathrm{C}, \mathrm{Ac} 3=855^{\circ} \mathrm{C}, \operatorname{Ar} 1=615^{\circ} \mathrm{C}, \operatorname{Ar} 3=$ $762{ }^{\circ} \mathrm{C}$. When the cooling rate is $0.028-4.25^{\circ} \mathrm{C} / \mathrm{s}$, the microstructure is ferrite and pearlite, in which the content of ferrite is relatively more and the content of pearlite is relatively less; when the cooling rate is $8.5-42.5^{\circ} \mathrm{C} / \mathrm{s}$, bainite transformation occurs, and the microstructure is ferrite, pearlite and 
bainite.

2) The hardness increases with the rising of the cooling rate. Hardness of $42.5^{\circ} \mathrm{C} / \mathrm{s}$ increases by $60 \mathrm{HV}$ compared with $0.028^{\circ} \mathrm{C} / \mathrm{s}$. The mechanism of microstructure transformation and hardness change of $12 \mathrm{Mn}$ steel under different cooling rates was analyzed, and the CCT was explained microscopically.

4) The CCT of 12Mn steel was simulated by JMatPro, and the trend was basically consistent with the measured CCT curve.

5) The high-temperature tensile strength of $12 \mathrm{Mn}$ steel round billet decreases with the going-up of temperature. Its mathematical model is as follows:

$\delta_{\mathrm{b}}=115.366+24355.136328 \exp (-0.01116 T)$.

6) The third brittle zone appears at $600-1000{ }^{\circ} \mathrm{C}$, and the reduction of area decreases to the lowest point at $900{ }^{\circ} \mathrm{C}$. The Ra value is only $40 \%$. The reason of grain boundary embrittlement in the third brittle zone is the precipitation of AlN particles, which has been verified by Thermal-cal.

7) The stress-strain curves of $12 \mathrm{mn}$ round billet at different test temperatures are analyzed. The results show that the stress increases gradually with the increase of temperature, then decreases, and finally tends to level.

\section{Acknowledgements}

The authors are grateful for financial supporting and experimental help from both Tianjin Iron and Steel Group Co., Ltd., Tianjin, China and Central Iron and Steel Research Institute, Beijing, China.

\section{References}

1.Liu H, Zhong D Z, Zhao L Q, et al. Continuous Cooling Transformation Behavior of High Strength Low-Alloyed Cold 
2.SONGDong-li, GUJian-feng, ZHANGWei-min, et al. Numerical Simulation on Temperature and Microstructure during

Quenching Process of Large-sized AISI P20 Steel Die Blocks[C]// Congress of International Federation for Heat Treament \&

Surface Engineering. 0.

3. Liu C B , Zhai Z L, Dou S P, et al. Banded structure of a gear steel SAE8620H[J]. Cailiao Rechuli Xuebao/Transactions of Materials and Heat Treatment, 2015, 36(2):155-161.

4. Salari S, Saeed-Akbari A, Naderi M, et al. Martensitic Transformation Behavior of B-Bearing Steel During Isothermal Deformation[J]. Steel Research International, 2012, 83(8):0-0.

5.Shi Z, Liu K, Wang M , et al. Effect of non-isothermal deformation of austenite on phase transformation and microstructure of 22SiMn2TiB steel[J]. Materials Science and Engineering, 2012, 535(Feb.15):p.290-296.

6.12Mn steel go up.SONGDong-li, GUJian-feng, ZHANGWei-min, et al. Numerical Simulation on Temperature and Microstructure during Quenching Process of Large-sized AISI P20 Steel Die Blocks[C]// Congress of International Federation for Heat Treament \& Surface Engineering. 0.

7.Hong-Ying L I, Geng J F, Zheng Z Q, et al. Continuous cooling transformation curve of a novel Al-Cu-Li alloy[J]. Transactions of Nonferrous Metals Society of China, 2006, 16(5):p.1110-1115.

8. Pussegoda L N , Malik L, Morrison J . Measurement of Crack Arrest Fracture Toughness of a Ship Steel Plate[J]. Journal of Testing and Evaluation, 1998, 26(3):187-197.

9. Pavlina E J , Tyne C J V . Correlation of Yield Strength and Tensile Strength with Hardness for Steels[J]. Journal of Materials Engineering \& Performance, 2008, 17(6):888-893.

10. Mintz B , Yue S, Jonas J J . Hot ductility of steels and its relationship to the problem of transverse cracking during continuous casting[J]. International Materials Reviews, 1991, 36(1):187-220.

11. Maehara Y, Ohmori Y. The precipitation of $\mathrm{A} 1 \mathrm{~N}$ and $\mathrm{NbC}$ and the hot ductility of low carbon steels[J]. materials science \& engineering, 1984, 62(1):109-119. Gamsj?Ger E, Svoboda J , Fischer F D . Austenite-to-ferrite phase 
transformation in low-alloyed steels[J]. Computational Materials Science, 2005, 32(3-4):0-369.

12. Lankford W T. Some considerations of strength and ductility in the continuous-casting process[J]. Metallurgical Transactions, 1972, 3(6):1331-1357.

13. Lankford W T. Some considerations of strength and ductility in the continuous-casting process[J]. Metallurgical Transactions, 1972, 3(6):1331-1357.

14. Chen J, Young B . Stress-strain curves for stainless steel at elevated temperatures[J]. Engineering Structures, 2006, 28(2):p.229-239.

15. Roylance D. Stress-strain curves[J]. Massachusetts Institute of Technology study, Cambridge, 2001.

16. Chen J , Young B . Stress-strain curves for stainless steel at elevated temperatures[J]. Engineering Structures, 2006, 28(2):p.229-239.

17. Roylance D. Stress-strain curves[J]. Massachusetts Institute of Technology study, Cambridge, 2001.

18. Lankford W T J . Some considerations of strength and ductility in the continuous-casting process[J]. Metallurgical \& Materials Transactions A, 1972, 3(6):1331-1357. 